\title{
Universiteit
}

Leiden

The Netherlands

\section{Queerness in the digital age: a scholarly roundtable}

Connolly, M.; Phillips, A.; Shield, A.D.J.; Tongson, K.

\section{Citation}

Connolly, M., Phillips, A., Shield, A. D. J., \& Tongson, K. (2020). Queerness in the digital age: a scholarly roundtable. The Velvet Light Trap, 86, 49-56. doi:10.7560/VLT8606

Version: $\quad$ Publisher's Version

License: $\quad$ Licensed under Article 25fa Copyright Act/Law (Amendment Taverne)

Downloaded from: https://hdl.handle.net/1887/3201097

Note: To cite this publication please use the final published version (if applicable). 


\section{PROJECT MUSE}

Queerness in the Digital Age: A Scholarly Roundtable

Matt Connolly, Amanda Phillips, Andrew DJ Shield, Karen Tongson

The Velvet Light Trap, Number 86, Fall 2020, pp. 49-56 (Article)

Published by University of Texas Press

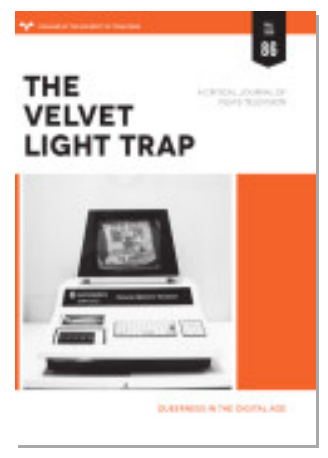

$\Rightarrow$ For additional information about this article

https://muse.jhu.edu/article/765114 


\section{QUEERNESS IN THE DIGITAL AGE A SCHOLARLY ROUNDTABLE MODERATED BY THE EDITORS}

F OR THIS ISSUE ON QUEERNESS IN THE DIGITAL AGE, THE VELVET LIGHT TRAP GATHERED A diverse group of scholars with a range of specialties related to queer theory and media. The conversation that follows touches on everything from dating apps to the films of John Waters to a livestreamed Indigo Girls concert, demonstrating the myriad ways digitality has affected queer media, representation, and audiences. Apropos of an issue concerned with digital spaces, this roundtable took place via email. The editors began this roundtable on March 9, 2020, only for closures due to the COVID-19 pandemic to begin in earnest a few days later. Thus, the participants' contributions began to reflect this fraught period toward the end of the conversation.

This conversation has been edited for clarity.

MATT CONNOLLY is an assistant professor of film studies at Minnesota State University, Mankato. His work explores the intersections of the American film industry and LGBTQ cinematic history. He is currently revising his dissertation on the work of John Waters. His scholarly work on LGBTQ cinematic history has been published in Cinema Journal and Spectator, and he writes film criticism for Film Comment and Reverse Shot.

AMANDA PHILLIPS is an assistant professor in the Department of English and the Film and Media Studies Program at Georgetown University. Her book Gamer Trouble: Feminist Confrontations in Digital Culture looks "under the hood" of video games to understand how difference and identity are baked into gaming's mechanisms, ideologies, and social systems. Her work has been published in Feminist Media Histories, Game Studies, Games and Culture, and more.

ANDREW DJ SHIELD is an assistant professor at the Institute for History at Leiden University. He is the author of Immigrants in the Sexual Revolution: Perceptions and Participation in Northwest Europe and Immigrants on Grindr: Race, Sexuality and Belonging Online. He is part of the interdisciplinary research team Social Citizenship and Migration and a cofounder of the Leiden Queer History Network.

KAREN TONGSON is a professor of English, gender and sexuality studies, and American studies and ethnicity at the University of Southern California. She is the author of Relocations: Queer Suburban Imaginaries and Why Karen Carpenter Matters and has upcoming monographs on karaoke and queer performance as well as "normporn" and constructions of normalcy on US television. She

DOI: $10.7560 /$ VLT8606 
also coedits the award-winning book series Postmillennial Pop with Henry Jenkins and cohosts the podcast Waiting to X-hale with Wynter Mitchell-Rohrbaugh.

VELVET LIGHT TRAP: What do you think is the state of queer theory and queer studies in light of contemporary media practices?

ANDREW DJ SHIELD: My first thought goes immediately to dating and hookup apps geared primarily at subsections of the LGBTQ+ community. The current field of "Grindr studies" (what I call scholarship related to apps geared primarily at gay/bi men and some trans/queer people) looks a lot at self-presentation strategies (how people communicate about their bodies, gender identities, ethnicities, safer sex strategies, etc.). I also look a lot at the culture of the apps and how (especially queer) people use "hookup apps" for a lot more than sex (such as for finding friends, jobs, rooms, local info).

Within the cultures of online, queer dating apps, individuals' profiles communicate a lot. Some are political, some confrontational, some challenge dominant categories and problematic discourses. Individuals broadcast their message, via their profiles, to an audience. Hence, I see parallels with other media (newspapers, web forums).

AMANDA PHILLIPS: In my own media corner, I think and write about video games, which have been really interesting to watch change over the last ten years or so. Like other media, we've seen a surge of representation of queer folks beyond the cis white gay men that had already made some inroads into cultural stories. On the mainstream front, major franchises like Assassin's Creed, Dragon Age, The Last of Us, and Mass Effect introduced queer and trans characters that differ from much of what came before: they are characters of color, they are women, they are protagonists, they don't have to die.

In some ways, however, the appearance of these new representations is a bit of an illusion. In December 2018, the Schwules Museum in Berlin put together the Rainbow Arcade, the first exhibit dedicated to queerness in video games, cocurated by Sarah Rudolph, Jan Schnorrenberg, and Adrienne Shaw. One of the messages of the exhibit is that queer representations in video games go back much further than we think. They even dug up queer games from the late eighties and early nineties! One of them, Caper in the Castro, is now available to play on the Internet Archive.

Representation inevitably leads to the question of creators, and efforts to diversify the industry and make it more welcoming for marginalized folks include hashtag campaigns like \#1ReasonWhy and \#1ReasonToBe, which were a sort of call-and-response starting in 2012 about sexism in the industry and why women nevertheless persisted. Today, there's a big push to unionize game workers, in large part because labor conditions like "crunch," in which workers are expected to work eighty to one hundred hours per week to finish a project, are a big reason that marginalized folks choose to leave the industry. There's a recognition here that what is good for the most vulnerable workers is good for all workers, though it's been an uphill battle for them. Game Workers Unite has been a huge influence here.

On the indie front, what Bo Ruberg's new book calls the "queer games avant-garde" exploded in the early 2010s, in which queer developers, most of them trans women, started creating small, quirky games-some about being trans and/or queer and some of them not. In some ways, they heralded the arrival of the mass media game representation, but they also initiated a larger conversation about working conditions, accessibility, and a shift away from the polished and photorealistic aesthetics of the mainstream games industry. Today, many of these folks are still developing, but many of them also have left games for various reasons. Many of the games that were widely praised at the time, like Anna Anthropy's Dys4ia and merritt k's Lim, are no longer available to play. Others, like Mattie Brice's Mainichi, are facing challenges with each subsequent update of OS X and probably won't be available for long. Meanwhile, a whole new generation of indie queer devs is coming up, and even larger teams of sometimes nonqueer folks are also starting to make queer games: I'm thinking of Dream Daddy and Genital Jousting here in particular.

As for games and queer theory, there are many of us in the academy who are pushing folks working on LGBTQ representation in games to think more broadly about structure, technology, affect, play, and other nonrepresentational aspects of games that line up with queer theoretical perspectives. There's been really great work done in all of these areas by folks like Aubrey Anable, 
micha cárdenas, Ed Chang, Whitney Pow, Teddy Pozo, Kara Stone, and more. We haven't quite gotten to the place where queer theory is picking up game studies instead of vice versa, but there are really compelling scholars and artists out there making the case for this, and I wouldn't be surprised to see it happening soon.

SHIELD: Video games are far from my area of expertise, but I'm a big fan of the scholarly work of Lisa Nakamura. Over the years, she's commented on the fact that diverse avatars don't necessarily equate to the breaking down of stereotypes (e.g., white men choosing female Asian characters to masquerade as "horny geishas" in an online world).

Have you seen that (problematic "identity tourism") at all with the games you work with? Are your games more geared at queer and people of color crowds?

I actually see parallels with internet and dating cultures. Sexual racism is (obviously) a huge component when looking at how people talk about race and sexuality. There's also, to a smaller extent, some aspect of "gaming" by way of avatar choosing, such as users who make fake dating profiles - not necessarily to be deceptive but more just to "try on" another character/race/gender. "Identity tourism" (as Nakamura and others have called it) can be liberating, can also be stereotype-affirming, can be both, neither...

KAREN TONGSON: As "the old" in this group of interlocutors, I'll start by answering the first question prompt from the other side of where many of you began (with reflections on the state of "contemporary media practices" viz. queerness, from dating apps to video games, etc.). In other words, I'd like to start with the state of queer studies as a field, and how it addresses — or fails to address — contemporary media practices from any true "media studies" vantage point. I think as someone primarily oriented in queer cultural studies work, the pattern I see is that contemporary media practices are still taken up in the field as a set of discrete objects, prime for methods of "queer reading." Meanwhile, media studies in its continued transformations has pressed us, and rightly so, on addressing queer media as media as opposed to further objects to which to apply queer reading practices/textual analysis derived primarily from literary studies or early iterations of film and media studies.
For example, we take up queer TV programming with a thematic lens, reading for "representation," realism, and an attention to plot (I'm thinking especially about recent series like The L Word: Generation Q, Work in Progress, or even something like Transparent). Meanwhile, the prevailing discourse in queer studies, versus, say, queer media studies, fails to take into account even the simplest production practices and transformations these shows index, while staying focused only on the level of "representation."

I hear Amanda taking some of these issues up in their brief genealogy of video game studies, as well as in Andrew's response to that post by invoking the complexity Lisa Nakamura has tried to bring to discussions of online avatars, and the failures of representation.

I'd be curious to hear what you all think of this fundamental disjuncture between the state of these fields (plural) and their seeming incommensurability. Will traditional queer studies methods consistently fail at efforts to engage more completely the range of contemporary media practices, and how do we get media studies to assert its contributions to capital-Q Queer Studies?

MATT CONNOLLY: On the initial question of the state of queer theory / queer studies in light of contemporary media practices, I will confess to feeling a bit luddite-ish within this roundtable, in that my own research tends to hew primarily to film and focuses more specifically on LGBTQ cinema in the United States from the 1960s to 1970s. So, when I think of the recent scholarship that has most directly impacted my own thinking and writing — for instance, Ryan Powell's Coming Together: The Cinematic Elaboration of Gay Male Life, 1945-1979 or Chris Holmlund's monograph on John Waters's Female Trouble - it tends to both address topics and utilize methodologies that do not intersect with the "digital" in obvious ways.

That said, I have been thinking more and more about how digital interfaces and means of communication / social networking interact with both older cinematic images and more "traditional" methods of research and scholarship. To the first point, I think that digital streaming platforms have both provided an exciting means of circulating older queer cinema (everything from specialized sites like Dekkoo to queer-related titles on broader services like the Criterion Channel, never mind the behemoths of Netflix and Amazon) and inculcated the frustrating mentality 
of "If it's not streaming, it doesn't exist." Amanda, I'm curious if this aligns with your experience regarding video games that seem to disappear from online circulation?

Additionally, I'm interested in how contemporary social media offers ways to recirculate images from older queer cinema, either as a means of addressing the referred-to cinematic title explicitly or to appropriate and/or recode the message for other purposes. (As a researcher into John Waters, for instance, I'm struck by how often images of Divine and Waters himself pop up in the social media feeds of various users, queer and not.) Generally, I'm curious as to what you all think of these digital uses of older cinematic imagery. Andrew, do you see the circulation and reappropriation of cinematic and/or media imagery within the context of app usage?

Finally, I am heartened by the (hopefully!) continual expansion of older queer publications and archival resources into the digital realm. To point to but one example: the Independent Voices project-an "open access digital collection of alternative press newspapers" available at voices.revealdigital.org-offers a free and searchable archive of over seventeen thousand issues of alternative newspapers from the latter twentieth century, including many LGBTQ publications. The no-cost availability of such materials (unencumbered by either paywalls or the logistics and cost of travel to physical archives) seems an unalloyed good.

As a means of concluding this (long!) response, I want to connect these trends to Karen's wonderful point about distinctions between more textual/analysis-based modes of queer scholarship and modes that consider production, circulation, and questions beyond explicit textual representation. My points above perhaps reveal my own interest in questions of circulation and reception with regard to the study of queer film and media. How much do you think such considerations are centered within your specific fields?

SHIELD: Karen, thanks for your addition addressing queer studies as a field and how it addresses-or fails to address - contemporary media practices from any true "media studies" vantage point, which, in Matthew's words, helps clarify distinctions between textual analysis and modes that consider production, distribution, exhibition, and reception. I think this was an important clarification of the overall framework for our discussion, and I'll have to think more about this. To be honest, I have been fortunate enough to join the field of "media studies" after decades of queer contributions. So a good portion of my understanding of media studies (e.g., virtual ethnography and the ethics thereof) comes directly from queer (and/ or feminist) scholarship.

Matthew, thanks for voices.revealdigital.org. Does anyone use the Gale archive on LGBT culture, 1945-1990s (www.gale.com/c/archives-of-sexuality-and-gender -lgbtq)?

I was able to convince my uni to buy it, and there are terrific periodicals in it. (A student of mine analyzed the 1970s journal Drag, for example.) I used this same resource on microfiche when I was a grad student and love that it's been digitized; however, I think there are some ethical (and legal?) issues with Gale selling and profiting off digitizing queer grassroots publications. Many of the writers/photographers are alive, and nobody from Gale attempted to contact them to request permission to reprint their contributions, or to offer remuneration.

On older campy media representations recirculating in contemporary media, Matthew asked about the circulation and reappropriation of queer cinematic or media imagery within the context of app usage. I love this question! I would love to see a Grindr profile casually stating, "Filth are my politics, filth is my life!" Divine is definitely alive and well among certain subsets of the "young" queers. But unfortunately, the "oldest" references I tend to see are probably from Mean Girls. Though I have seen the occasional "You're terrible, Muriel!"

CONNOLLY: I think all of us have likely felt the effects of COVID-19-related social and professional disruptions over the past couple of days. Rereading some of the previous posts, however, I began to think about how the coronavirus pandemic might illuminate and/or bring to light questions tied to queer studies and contemporary media practices.

Andrew, I of course started thinking about the impact that the coronavirus will have on the sexual and social economies of queer dating and hookup apps: the effect on the physical interactions that those apps often facilitate, 
but also on the alternate forms of erotic and interpersonal connections that might be fostered or intensified by a heightened anxiety surrounding physical proximity. What do you think the ripple effects might be?

Amanda, I'm also curious about the role of video games and online gaming in the midst of a pandemic. On the one hand, access to such games would seem ideal for the "self-quarantine" moment of home entertainment. On the other hand, I wonder to what extent the social and economic disruptions of coronavirus might be complicating the communities (either physical or digital) that surround gaming practices. And, given your earlier points about the increased understanding of the game industry's often punishing work schedules and labor commitments, how do you think that the industry will be affected by increased calls for social distancing and working away from the office?

Both of these sets of queries, to my mind, point to something that has always felt intrinsic (if by no means exclusive) to the study of queer film and media — the role of community and queer collectivity. This, I think, gets to Karen's point about the distinctions between a primary focus on text-based representational analysis and a mediafocused analysis that takes into account how modes of production, distribution, exhibition, and reception shape the understandings of said textual representation. If these factors seem to me to have particular importance for an understanding of queer media, it is partly based on the fact that queer people frequently have to both collectively shape alternate understandings of mainstream media texts and construct alternate industrial structures and practices to make the media that most fully reflects and contends with queer life. To isolate a media text from those contexts can still produce valuable insights while at the same time seem to obviate key factors. Karen, do you find this to align with your own thinking on queer methodologies?

As a note of closing, I've been thinking about the resources that queer film and media (and queer film and media studies) of the past can offer at this moment. My mind has returned frequently to the HIV/AIDS epidemic. To be clear, HIV/AIDS and COVID-19 are very different phenomena-in their medical nature, means of transmission, social and political valences, etc. At the same time, the issues that activists and theorists (who were often the same people) explored at the height of the HIV/AIDS epidemic in the United States have strong echoes in the rhetoric of today. Most notably, contemporary activists, commentators, and everyday observers are using the extremity of the coronavirus pandemic to make an argument about the broader social and political failings that exacerbate its spread: faulty social-safety nets, limited health care options, a turning inward toward bigotry and small-mindedness in the face of social contagion. Consciously or not, these are ideas that people of today are picking up from HIV/AIDS activism and scholarship from thirty years ago.

It raises some similar (though not identical) questions, as well, about the status of queer communal life, spaces, and practices in an era of social distancing and anxiety. One of the huge differences, of course, is the role of digital and online spaces as another site of community building, support, and comfort. But, I suppose, the question I'm left with is how even those spaces might be impacted.

PHILLIPS: The Game Developers Conference was actually one of the first events on my radar to be canceled, though only after major developers like Microsoft, Sony, and others pulled out. I don't know enough about the inner workings of the industry to say how they're handling it, but I have been struck by the prevalence of folks shifting to gaming platforms like Twitch and Discord in the scramble to shift classes online. I think the general perception is that these platforms are already proven effective with that kind of bandwidth. As with all platforms, they come with their disadvantages: beyond the monetization of your labor, there is the concern that Discord has facilitated the incubation of the Far Right, for example.

I work primarily on mainstream pop culture games, so I'm trying to think about queerness from a lot of games that didn't necessarily have queer folks in mind, or that provide a bare minimum of "diversity" to appeal to a certain kind of demographic. This of course means that a lot of identity tourism happens, though I remain hopeful about the potential of games to disturb the way we think about identity. A lot of times folks don't take seriously that cross-gender and even cross-racial avatar identification are powerful sites to think about this stuff. I recently finished a manuscript thinking about multiracial avatars and science fiction memory manipulation games, in which 
I found that what we often identify as identity tourism can provide a way for white folks to be heroes of racial justice in the past (for example, in games like Assassin's Creed that let you do things like participate in subverting the Crusades or Caribbean enslavement) and absolve contemporary whiteness of the sins of the past, but also that the brown- or Blackness of the multiracial avatars is always there reminding the players of these buried histories. With gender, you'll find weird moments like how men will claim they only like playing as Lara Croft to protect her or stare at her ass, but then will shriek uncontrollably playing something like Genital Jousting (It's real, go play it!) when their virtual dicks get poked by cacti. I think there are many different ways to relate to an avatar but relatively few folks who take that superseriously beyond discussing things like the male gaze.

In terms of community and coronavirus, I have also been feeling the weight of and appreciation for queer folks who have seen epidemics before. I've also been connecting with local queer family to reinforce that "we got us." My final outing before \#socialdistance was to a local dyke watering hole. Thinking about all the gathering spaces that need to shut down to flatten the curve, I despair a bit for the folks who rely on those spaces for community. I know there's been a prevalent narrative about apps killing queer hangout spots, though I'm not expert in this area and would love to hear more about it!

For me, gaming can play a part in maintaining connection: a good friend and colleague of mine just reached out to say that we should take advantage of the opportunity provided by more home time to catch up by playing games. As a gamer, I've always been better about keeping up with folks via play rather than on the phone.

SHIELD: Did anyone else see the sarcastic "queering the quarantine" memes? (Basically: how long until we get a special issue about...)

That being said, I had already scoured the internet for "queer corona" articles and was impressed with how quickly they appeared. First concerns were that LGBTQ+ people are more vulnerable, that is, more likely to have HIV and/or cancer (and/or lack of health insurance, in the United States).

Much less pressing, however, is the effect on "cruising" and casual/anonymous sex. It's not the most dramatic request to ask queers to refrain from finding casual partners for a month or so; but you're right that any restrictions certainly get at the heart of queer online sex practices (i.e., where the purpose of the online community is to facilitate "real-life" interactions).

As you wrote, Matthew, "HIV/AIDS and COVID-19 are very different phenomena-in their medical nature, means of transmission, social and political valences, etc.," but there are certainly parallels. Amanda, I think you agree: "I have also been feeling the weight of and appreciation for queer folks who have seen epidemics before" just underscores the need to conduct oral histories (e.g., about the onset of HIV) while they're still possible. (I'm an historian :))

I am a major advocate against the claim that apps killed queer spaces. (Perhaps they play a role, but I definitely blame gentrification foremost.) My main arguments (against the idea that apps killed the queer bar/space) are:

1. People use apps and queer spaces differently. Maybe they cruise for sex on apps, but they meet their friends on a Thursday evening at a bar for drinks. Also, some people cruise on apps and then meet their date at a queer bar. Tourists often prefer the latter if they're looking for a "tour guide" to show them around the city (in tandem with a hookup).

2. People use apps in queer spaces. It's not uncommon to have people "seeing who's around" while inside a queer bar/ space. This might sound antisocial, but for some people, it's easier to say "hello" on an app than in real life. Maybe they'll eventually do both. Again, this is often true for newcomers (tourists and immigrants).

3. Many people have better luck finding sex off-line. This is similar to number 1 but just emphasizes that lots of people find that their best attributes (humor, charm, tone of voice) shine through "in real life." This is especially true in light of conversations about sexual racism, where some app users are immediately rejected because of, e.g., race.

VELVET LIGHT TRAP: Along with continuing to answer one another's questions, to wrap up, what would you say is the utility in taking a queer approach to the study of digital media? What does the future hold for the study of queerness in the digital age, or what do you hope the future holds?

CONNOLLY: Amanda, as someone who tries to practice a similarly critical-yet-capacious approach to viewer 
identification, I am really interested by how you describe the range of ways that players relate to their avatars. (I'm not much of a gamer myself, but Genital Jousting might have to go on my list of quarantine media.) I also very much sympathize with the anxieties surrounding the status of queer spaces during what might be a prolonged shutdown of communal gathering spaces more generally. That said, both your and Andrew's comments make me appreciate the already-hybridized nature of my own queer sociality. Especially having moved to a town without a designated gay bar, that often involves gathering with queer friends at "de facto" queer spaces while at the same time continually conducting group chats and occasional digital meetups with farther-flung queer groups. While I fear the potential for an extended pause in physical queer gatherings to (in my mind) erroneously support an argument for their "irrelevance," I am also grateful for how previously utilized digital platforms can be leaned on during this time to pick up some of that slack.

In terms of the futures of queer media studies, I think my main concern/hope centers on the role of streaming platforms and their presumed centrality in the creation and circulation of queer film and media. This is a generalized thought, though the even greater reliance on digital platforms in a time of social distancing perhaps makes this feel even more central. In short, I think one of the most urgent goals of a queer approach to the study/future of digital media lies in adopting a clear-eyed view of what streaming platforms like Netflix and Amazon Prime offer and what their very real limitations are.

On the one hand, I cannot deny that a site like Netflix has funded, distributed, and amplified some important pieces of queer media over the past decade. Furthermore, both larger sites and more specialized streaming platforms have made LGBTQ cinema more broadly available to a wider range of viewers than if it remained solely within the channels of small theaters or even physical home-video media. Discussions with students attest to this when they talk about "stumbling upon" recently produced queer films.

At the same time, I worry about two overlapping forces linked to these trends: the broad centralization of practices (i.e., if it's not on Netflix, it is functionally "not available"), and the sometime aura of beneficence that seems to accrue around them for supporting queer media. Taken together, I'm concerned that these can lead to a broader contraction about where we go to see queer media and what we deem to be challenging, worthy, and vital within queer media. I think one can see a version of this in the "exclusively gay" moments of recent blockbuster cinema as well-the mere presence of representation within mass-produced and -marketed works being taken as an unalloyed good as opposed to a piece of the representational mosaic to be evaluated and critiqued as such.

Of course, there are plenty of people both within and beyond the academy who do good work on this frontcontextualizing and judging mainstream representation; criticizing the strengths and limitations of streaming services' capacities, reach, and blind spots. Most crucially, I think it's queer media studies' job to constantly remind people of the ever-expansive range of queer film and media and the multifarious ways in which it can be accessed, analyzed, and communally understood. To me, the history of queer film and media studies has always been a balancing act of working through queer understandings of mainstream texts and a critical highlighting of alternative modes of queer production, distribution, exhibition, and reception. As we settle into a period where it seems like a handful of home-based digital platforms can loom larger than ever, I think that's an important legacy to remember and continue.

TONGSON: I wanted to frame my participation, or lack thereof, in this thread, because I can't remember such an accelerated set of epochal shifts in such a brief, yet also extended and extending, period of time in my entire life, since probably $9 / 11$, though I think this moment is even more paradigmatically transformative in a profound and disturbing way. Our own conversation here has shifted dramatically, and by necessity, to account for the very real and urgent forms of improvised "remote intimacy," a concept I wrote about in my first book, Relocations, that tracks asynchronous, predigital, often broadcast media experiences that coalesced later into "real life" points of connection and contact among spatially scattered suburban subjects. To be honest, it's a very "Gen X" / "Xennial" point of view on how queer media is absorbed into the matrices of sociability and desire in a broader sense through those archives of knowing. In fact, I tend to still operate on the assumption that analog media genres and forms are the basis or the training ground for our efforts to forge other 
coalitions and craft new queer of color worlds into being despite (or maybe even because of?) our asynchrony.

As we mourn our last nights out for the foreseeable future-I'm thinking here of Amanda's last drink at the local dyke bar, or Matt swooping in from air travel, or the many gatherings referenced here, both professional and un-, that have been \#CanceledbyCovid-I'm left wondering how we queers are going to adapt to a new (and deadly) viral age. As Andrew has already argued, digitality and dating apps didn't kill or dampen the need to gather together in queer spaces, but became an enhancement to and facilitator within them. Is this where we're headed? Is "Who's zoomin' who?" going to be a question we all ask in our networks of queer gossip?

Even within the first few days, as states like California and New York go on lockdown, and as we continue to exist in our perpetual state of national emergency, I've also seen what even the most rudimentary of digital forms have done to revivify our queer spirits amidst our "selfisolation," sometimes without the promise of so much as a calming embrace if we live alone. The Indigo Girls livestreamed a concert on Facebook-certainly not the most advanced form of digital gathering, or the youngest/ coolest platform at all, which is totally in keeping with the temporal drag of lesbian cultures in general. But for that hour, over sixty thousand people popped in to watch with so much joy and exuberance, and it was like we were in the world's largest dyke bar, or back at Lilith Fair or Michfest (without all the wretched transphobia). Exes said hello to each other, dykes from coast to coast and everywhere in between waved to one another and shouted requests for "Chickenman" or "Strange Fire" into the group chat. And by the time they closed with "Closer to Fine" and "Galileo" at the end-two "sing-along songs," as Amy and Emily called them-so many of us were in tears, both real and emoji, because our anxious vigils for symptoms and all the physical distance imposed by state decrees were interrupted if ever so briefly. We were reminded then, as we were singing along to our screens, that we once slung our arms around each other swapping fluids through botched harmonies with reckless abandon. And we hoped with all hopes that we might someday be able to do it all again.

PHILLIPS: Andrew, thank you so much for a much better narrative about apps and queer spaces-I'll be sure to pull that out of my back pocket the next time someone grumps about it. And yes, Sundén's work is really valuable and interesting with respect to avatar identification, though it's a conversation I sometimes find difficult to have across humanities / social science lines. My head is often too far in the clouds, which is where I prefer it. This is something that we unfortunately don't have time to address further: the (often generative) frictions that pop up when working interdisciplinarily.

I think Karen's observations about the seismic shift are both terrifying and hopeful for me. In my own corner of the universe, there has been a tremendous amount of organizing (queer and otherwise) around supporting local community, donating to make sure precarious workers have enough for the essentials, even folks making instructional YouTube videos or volunteering to entertain children remotely for a precious hour or two. I'm trying to focus on that for now. As we continue to figure this out, I do have the utopian hope that we'll learn how to slow down. Maybe I'll even catch up on that backlog of games that I need to play. 